\section{REVISTA BRASILEIRA DE QUALIDADE DE VIDA}

\title{
Qualidade de vida no trabalho: conceito, histórico e relevância para a gestão de pessoas
}

\section{Quality of work life: concept, historical and relevance to people's management}

\author{
Cristiano Dal Forno \\ Pontifícia Universidade Católica do Rio Grande do Sul - PUCRS - Porto Alegre - Rio Grande do Sul - Brasil \\ cristiano_d_forno@hotmail.com \\ Igor da Rosa Finger \\ Pontifícia Universidade Católica do Rio Grande do Sul - PUCRS - Porto Alegre - Rio Grande do Sul - Brasil \\ igorrf@unisinos.br
}

\section{RESUMO}

OBJETIVO: Compreender a evolução do conceito de Qualidade de Vida no Trabalho (QVT) e de sua relevância para as organizações atuais.

MÉTODO: Por meio de revisão teórica, faz-se uma incursão pelo histórico da QVT até sua consolidação, revisam-se as proposições de alguns de seus principais teóricos e se apontam algumas das implicações de ações na área de QVT na Gestão de Pessoas, apresentando resultados de três estudos produzidos na última década.

RESULTADOS: Verifica-se que a complexidade da avaliação da QVT e da elaboração de intervenções nesta área está diretamente relacionada ao fator individual que caracteriza o construto. CONCLUSÕES: Desvela-se a necessidade de estudos empíricos voltados para a aferição e compreensão dos resultados concretos de projetos de QVT.

PALAVRAS-CHAVE: Qualidade de vida. Trabalho. Gestão de pessoas.

\section{ABSTRACT}

OBJETIVE: Understanding the evolution of quality of work life (QWL) concept and its relevance for today's organizations.

METHODS: Through the theoretical review, an incursion into the history of QWL to its consolidation is done, besides a review of the propositions from major theorists and some notes of actions in the area of QWL in People Management, presenting results from three studies produced in the last decade.

RESULTS: It is apparent that the complexity of the QWL evaluation and the development of interventions in this field is directly related to the individual factor that characterizes the construct.

CONCLUSIONS: Unveil is the need for empirical studies aimed at measuring and understanding the concrete results of QWL projects.

KEYWORDS: Quality of life. Work. People's management. 


\section{Introdução}

A atividade laboral é extremamente relevante para a manutenção da vida dos indivíduos, contribuindo para sua sobrevivência e adaptação ao mundo. Tendo em conta que uma parcela significativa da vida é passada no ambiente de trabalho, é essencial que os indivíduos sintam-se bem neste (DESSEN; PAZ, 2010). Diante disso, o tema da qualidade de vida (QV) ${ }^{1}$ assume importante relevância no âmbito das corporações.

As organizações tomaram parte na discussão e aplicação desse conceito na tentativa de planejar, implantar e avaliar alternativas de produção que permitam maior satisfação, bem-estar e saúde aos seus colaboradores, vislumbrando, dentre outras consequências, melhoras na produtividade, nas entregas e na rentabilidade.

Surge, então, um novo conceito, advindo do primeiro. Trata-se da Qualidade de Vida no Trabalho (QVT). Através da proposta de um enfoque biopsicossocial, Limongi-França (1997, p. 80) define QVT como sendo "[...] o conjunto das ações de uma empresa que envolve a implantação de melhorias e inovações gerenciais e tecnológicas no ambiente de trabalho". No Brasil, o tema vem causando interesse em empresários e em administradores, devido às contribuições que pode oferecer para a satisfação do empregado e para a produtividade empresarial (LIMONGI-FRANÇA, 2008).

Monteiro et al. (2011) apontam que no atual momento do mercado, caracterizado pela alta competitividade e pela grande demanda por profissionais qualificados e hábeis para darem conta dos desafios sempre novos, a QVT afigura-se como necessidade e resposta do indivíduo e como estratégia gerencial da organização.

Conforme Saraji e Dargahi (2006), níveis elevados de QVT são essenciais para que as organizações continuem a atrair e a reter funcionários, o que se configura em um problema complexo, pois, segundo os autores, é difícil identificar e isolar todos os elementos que afetam a QVT. Parece haver consenso entre os diversos autores de que a QVT integra a série de mudanças que estão ocorrendo nas organizações na sociedade atual, de maneira que seu processo de discussão transcende a área da saúde e se vincula às áreas da Administração, da Psicologia, da Sociologia, a partir de um enfoque multidisciplinar humanista (MONTEIRO et al., 2011; LIMONGI-FRANÇA, 2008; SARAJI; DARGAHI, 2006).

Ainda que a QV em geral e a QVT sejam distintas entre si, elas se relacionam e se influenciam mutuamente, de modo que dissabores no trabalho podem trazer como consequências desajustes na vida familiar e nas relações sociais fora do trabalho, bem como conflitos pessoais atrapalham a atividade laboral (SAMPAIO, 2004 apud VELOSO; SCHIRRMEISTER; LIMONGIFRANÇA, 2007).

Devido à importância que assume no enlace social, sobremodo no âmbito organizacional, constitui-se como objetivo do presente estudo compreender a evolução do conceito de QVT e de sua relevância para as organizações atuais. Para tanto, nas páginas que se seguem, far-se-á, através de revisão teórica, uma incursão pelo histórico do conceito até sua consolidação e se apresentarão proposições de alguns de seus principais teóricos, bem como algumas de suas implicações na Gestão de Pessoas, expondo resultados de três estudos.

\section{Breve histórico dos estudos de Qualidade de Vida no Trabalho}

A QVT teve sua origem na esfera privada, no ambiente empresarial que, histórica e progressivamente, tem se tornando mais competitivo. Verifica-se que, em um cenário de competição global, as pessoas, sobremaneira aquelas que dispõem de conhecimentos e habilidades,

\footnotetext{
${ }^{1}$ Como QV entende-se "[...] a percepção do indivíduo de sua posição na vida, no contexto de sua cultura e no sistema de valores em que vive e em relação a suas expectativas, seus padrões e suas preocupações" (THE WHOQOL GROUP, 1995).
} 
ganham importância estratégica no projeto de desenvolvimento de vantagem competitiva das corporações, de modo que a QVT tem sido, muitas vezes, utilizada para elevar o nível de satisfação dos colaboradores a fim de que estes se comprometam, ainda mais, com os processos e com os objetivos organizacionais (GARCIA, 2010).

O interesse do universo empresarial pela QVT data de mais de meio século. Todavia, foi a partir da década de 1970 que a QVT passou a ser considerada com maior atenção e a receber investimentos, principalmente nas grandes corporações, já que se vivia a crise estrutural nos padrões de acumulação taylorista - fordista e novas alternativas precisavam ser encontradas para a competição que se apresentava (FERREIRA; ALVES; TOSTES, 2009).

A QVT tem ocupado a atenção do homem desde o inicio de sua existência. Considerem-se os ensinamentos de Geometria de Euclides de Alexandria, aplicados na melhoria do método de trabalho dos agricultores à margem do Nilo e, também, a lei da alavanca da Arquimedes, que desde o ano 287 a.C. contribui para a diminuição do esforço físico dos trabalhadores, melhorando, assim, sua QV (MONTEIRO et al., 2011; RODRIGUES, 1999).

Entretanto, o termo QVT, propriamente dito, começou a ser utilizado na década de 1950, na Inglaterra, quando Eric Trist e colaboradores, do Tavistock Institute, realizaram estudos das relações existentes na tríade indivíduo-trabalho-organização, desenvolvendo uma abordagem sociotécnica da organização do trabalho que objetivava amainar o sofrimento da vida dos trabalhadores, a partir da reestruturação das tarefas (FERNANDES, 1996; RODRIGUES, 1999).

No entanto, foi somente na década de 60 que se observou a retomada de interesse pela QVT, a partir do desenvolvimento de estudos acerca das melhores formas de realizar o trabalho, com foco na saúde e no bem-estar geral dos trabalhadores (ANGRAD, 2012).

Nesse momento, os elementos relacionados ao aumento da produtividade e os índices relativos às aspirações e às necessidades pessoais ganharam relevância, consequência do desafio imposto pela necessidade de produtividade e de bom desempenho econômico-financeiro, fruto da competitividade internacional (MONTEIRO et. al., 2011).

Nadler e Lawler (1983 apud BOWDITCH; BUONO, 1992; GARCIA, 2010) referem-se a esta retomada de interesse pela QVT, que se prolongou até meados de 1970, nos Estados Unidos da América (EUA), como sendo o primeiro ciclo, quando outras preocupações, tais como descontrole da inflação e custo da energia, desviaram a atenção dos pesquisadores, causando novamente diminuição de interesse pelo tema. A retomada, isto é, o segundo ciclo de interesse na QVT, ocorreria, de acordo com os autores, somente a partir de 1979, alavancada pela convicção de que algo precisava ser feito para melhorar a produtividade frente à concorrência internacional aumentada pelos novos modelos gerenciais, tais como o japonês.

As atenções voltaram-se novamente para a QVT, quando muitos centros de estudos foram criados, nos EUA, a fim de desenvolver projetos nessa área. No início dos anos de 1980, a QVT voltou a ocupar lugar de interesse e preocupação no cenário nacional dos norte-americanos (BOWDITCH; BUONO, 1992), surgindo uma série de frentes de estudo com o objetivo de definir seu significado e os modos como poderia ser utilizada em prol das organizações (GARCIA, 2010).

O Quadro 1 apresenta as concepções evolutivas da QVT na visão de Nadler e Lawler (apud RODRIGUES, 1999): 
Quadro 1 - Concepções evolutivas da QVT

\begin{tabular}{|c|c|c|}
\hline PERÍODO & FOCO PRINCIPAL & DEFINIÇÃ̃O \\
\hline $1959 / 1972$ & Variável & $\begin{array}{l}\text { A QVT foi tratada como reação individual ao } \\
\text { trabalho ou às consequências pessoais de } \\
\text { experiência do trabalho. }\end{array}$ \\
\hline $1969 / 1975$ & Abordagem & $\begin{array}{l}\text { A QVT dava ênfase ao indivíduo antes de dar } \\
\text { ênfase aos resultados organizacionais, mas ao } \\
\text { mesmo tempo era vista como um elo dos projetos } \\
\text { cooperativos do trabalho gerencial. }\end{array}$ \\
\hline $1972 / 1975$ & Método & $\begin{array}{l}\text { A QVT foi o meio para o engrandecimento do } \\
\text { ambiente de trabalho e para a execução de maior } \\
\text { produtividade e satisfação. }\end{array}$ \\
\hline $1975 / 1980$ & Movimento & $\begin{array}{l}\text { A QVT, como movimento, visa a utilização dos } \\
\text { termos 'gerenciamento participativo' e } \\
\text { 'democracia industrial' com bastante frequência, } \\
\text { invocados como ideias do movimento. }\end{array}$ \\
\hline $1979 / 1983$ & Tudo & $\begin{array}{l}\text { A QVT é vista como um conceito global e como } \\
\text { uma forma de enfrentar os problemas de } \\
\text { qualidade e de produtividade. }\end{array}$ \\
\hline $\begin{array}{c}\text { Previsão } \\
\text { Futura }\end{array}$ & Nada & $\begin{array}{l}\text { A globalização da definição trará como } \\
\text { consequência inevitável a descrença de alguns } \\
\text { setores sobre o termo QVT. E para estes, a QVT } \\
\text { nada representará. }\end{array}$ \\
\hline
\end{tabular}

Fonte: Nadler e Lawler (1983 apud RODRIGUES, 1999, p. 81).

No Brasil, as ações voltadas para a QVT são mais recentes, acompanhando a abertura tardia do mercado nacional para importação de produtos estrangeiros e os aumentos de concorrência que lhe foram decorrentes, bem como a implantação de programas de qualidade total (FERNANDES, 1996).

Somente a partir dos anos 1980 alguns estudos começaram a ser realizados no território nacional, muitos influenciados, ainda, pelos modelos estrangeiros, com destaque para a Embrapa, em Brasília, e as Universidades Federais do Rio Grande do Sul e de Minas Gerais (ANGRAD, 2012; RODRIGUES, 1999). Nos anos 1990, assistiu-se a um incremento da produção científica brasileira sobre o tema (FERREIRA; ALVES; TOSTES, 2009).

Veloso, Schirrmeister e Limongi-França (2007) afirmam que, embora não haja um consenso conceitual, grande parte dos estudos apresentam a QVT como uma reação ao modelo taylorista. A QVT, originada na abordagem comportamental, é vista como a humanização no trabalho, na medida em que possibilita o bem-estar e a participação dos colaboradores nos processos decisórios. As iniciativas de QVT foram impulsionadas por exigências da sociedade, no que se refere, principalmente, ao aumento das preocupações com os direitos civis e à responsabilidade social das empresas (VELOSO; SCHIRRMEISTER; LIMONGI-FRANÇA, 2007).

\section{Principais referências do conceito de QVT}

Alguns autores, que constituem um seleto grupo, figuram como referência obrigatória em QVT. Suas teorias, consideradas clássicas e, simultaneamente, modernas e abrangentes, são largamente mencionadas na literatura e seus modelos utilizados em pesquisas acerca do tema. Walton, Westley, Werther e Davis, Hackman e Oldham, Lippitt, Nadler e Lawler, Huse e Cummings são tidos como os precursores da abordagem científica de QVT, ainda que suas proposições tenham sofrido críticas posteriores (FERREIRA; ALVES; TOSTES, 2009; GARCIA, 2010; LIMONGI-FRANÇA, 2008; STEFANO et al., 2006; VELOSO; SCHIRRMEISTER; LIMONGI-FRANÇA, 2007).

Para Walton (1973), QVT está diretamente relacionada ao atendimento das necessidades e aspirações dos sujeitos, a partir da humanização do trabalho e da responsabilidade social da 
empresa. O modelo que este autor propõe, atualmente utilizado na maioria das pesquisas de QVT, está sistematizado a partir de oito categorias de avaliação, quais sejam:

a) Compensação adequada e justa (relativa ao salário, considerando-se fatores como experiência e responsabilidade, talento e habilidade);

b) Condições de segurança e de saúde no trabalho (horários razoáveis, não exposição a condições prejudiciais à saúde, limite de idade para determinados trabalhos que exijam tal restrição);

c) Oportunidade imediata para utilização e desenvolvimento da capacidade humana (autonomia, exercício de múltiplas habilidades, informação e perspectivas, execução de tarefas completas e planejamento do trabalho);

d) Oportunidade futura para crescimento contínuo e segurança (possibilidades de promoção, progresso na carreira, desenvolvimento de novas habilidades, estabilidade/segurança no emprego);

e) Integração social na organização de trabalho (ausência de preconceitos e de estratificação, bom relacionamento interpessoal e integração);

f) Constitucionalismo na organização de trabalho (normas que estabelecem direitos e deveres dos trabalhadores, privacidade, diálogo, tratamento justo e direito a recurso);

g) Trabalho e espaço total de vida (equilíbrio entre o trabalho e a vida privada);

h) Relevância social da vida no trabalho (imagem que o trabalhador tem da organização e de suas práticas, o que leva à valorização ou à depreciação de seu próprio trabalho e carreira, com efeitos diretos na sua autoestima).

Na sequência histórica do estudo do conceito, identificam-se as contribuições de Hackman e Oldham (1975), para os quais a QVT está associada diretamente aos aspectos de motivação interna, satisfação e enriquecimento do cargo. Estes autores sugerem que as características da tarefa são determinantes no surgimento de três estados psicológicos:

a) Significância percebida (valor atribuído ao trabalho);

b) Responsabilidade percebida (relacionada aos resultados do trabalho);

c) Conhecimentos desses resultados, que, quando acessíveis, agregam em satisfação e motivação para os trabalhadores.

Ressalta-se que Hackman e Oldham (1975) desenvolveram o Job Diagnostic Survey (JDS) (Levantamento do Diagnóstico do Trabalho). O JDS operacionaliza o modelo teórico que propuseram e que possibilita verificar, a partir das atividades que compõem um determinado trabalho, se este necessita ser reestruturado com vistas à melhora da produtividade e o aumento da motivação do funcionário.

Poucos anos depois, na busca da compreensão do que influenciaria a QVT, Lippitt (1978) agrupou os oito critérios de Walton em quatro fatores chave, quais sejam:

a) O trabalho em si;

b) O indivíduo;

c) A produção do trabalho;

d) Funções e estrutura da organização.

De acordo com este autor, a aplicação de práticas de QVT dependeria do amadurecimento na organização e do desenvolvimento de um novo conceito de indivíduo, com suas reais necessidades, bem como de novos valores organizacionais, referenciados nos ideais humanísticos e democráticos (STEFANO et al., 2006; VELOSO; SCHIRRMEISTER; LIMONGI-FRANÇA, 2007).

Westley (1979), por sua vez, propôs um modelo que considera aspectos internos e externos à organização, relacionando quatro grupos de obstáculos que prejudicam a QVT. Segundo ele, esses teriam origem na natureza das organizações da sociedade industrial. O obstáculo político levaria ao sentimento de insegurança no emprego; o econômico, à injustiça no sistema de recompensas; o psicológico, à alienação; e o sociológico, à anomia. O autor esclarece que sintomas de insatisfação por parte do trabalhador podem estar relacionados a sentimentos de privação de igualdade e 
insegurança em seu ambiente laboral, do mesmo modo que sinais de alienação e anomia podem ser identificados a partir da indiferença com a tarefa, isto é, na falta de envolvimento com o trabalho.

Westley (1979) afirma, ainda, que tais problemas devem ser interpretados como categorias gerais que prejudicam a QVT, de modo que esforços concretos de humanização no trabalho cotidiano devem ser empreendidos em sua direção.

Para Werther e Davis (1983), os esforços para melhorar a QVT devem estar voltados em tornar os cargos mais produtivos e mais satisfatórios. Os projetos de cargos devem levar em conta os aspectos relacionados aos fatores ambientais, organizacionais e comportamentais, encontrando a justa medida de respeito pelas limitações e exploração do potencial dos trabalhadores. O modelo proposto por eles articula-se a partir de variáveis tais como supervisão, condições de trabalho, pagamento, benefícios e projeto de cargos, por entender que são estas que afetam diretamente a QVT, considerando, que é a natureza do cargo que envolve mais intimamente o trabalhador.

Nadler e Lawler (1983 apud STEFANO et al., 2006) contemplam a QVT a partir da participação dos funcionários nas decisões, reestruturação do trabalho através do enriquecimento da tarefa, inovação no sistema de recompensas e melhorias no ambiente de trabalho. Nadler e Lawler (1983 apud RODRIGUES, 1999) afirmam que, provavelmente, o fator determinante de sucesso e de viabilidade dos esforços de QVT está relacionado com a estrutura dos processos participativos criados na organização. Veloso, Schirrmeister e Limongi-França (2007) referem que, para esses autores, a QVT é uma maneira de pensar a respeito das pessoas, do trabalho e das organizações.

Garcia (2010), por sua vez, destaca como ponto importante dessa concepção o fato do foco da QVT não estar somente no modo através do qual os trabalhadores podem desempenhar melhor a tarefa, mas em como o trabalho pode contribuir para tornar as pessoas melhores, permitindo que participem do processo de tomada de decisão organizacional naquilo que as afeta, o que é diferente de afirmar que todas as decisões da organização devam ser participativas.

Finalmente, concluindo o grupo de pesquisadores estrangeiros, dá-se destaque às contribuições de Huse e Cummings (1985), cujo modelo é bastante semelhante ao proposto por Nadler e Lawler (1983). A atenção ao bem estar do trabalhador, a sua participação nas decisões e problemas do trabalho e a eficácia organizacional são, de acordo com estes autores, os principais aspectos a serem considerados pela QVT. Sugerem que o trabalhador possa participar dos processos de tomada de decisão, do projeto de reestruturação de cargo e da melhora no ambiente de trabalho.

No cenário nacional brasileiro, destacam-se os trabalhos de Fernandes (1996), que analisa a QVT a partir de fatores que tornam os cargos satisfatórios, propondo o modelo conhecido como Auditoria Operacional de Recursos Humanos para melhoria de QVT, fortemente influenciado pelos modelos de Walton e Westley, em uma espécie de sistematização simplificada destes, em quatro grupos de fatores de natureza:

a) Econômica;

b) Política;

c) Psicossocial;

d) Logística.

Registra-se, também, a relevante contribuição de Limongi-França (2008), para quem a QVT deve visar, principalmente, a busca do equilíbrio físico/biológico, psíquico e social dos trabalhadores, no contexto organizacional do trabalho, inaugurando, desse modo, no Brasil, o paradigma biopsicossocial organizacional em QVT e propondo ações integradas que levem a um crescimento pessoal e organizacional.

\section{A Qualidade de Vida no Trabalho como ferramenta da Gestão de Pessoas}

A QVT, seja como campo de estudo e reflexão seja como programas práticos de intervenção social, tem, progressivamente, despertado o interesse dos responsáveis pela Gestão de Pessoas, que perceberam nas iniciativas relacionadas à área um método eficaz de proporcionar bem-estar aos trabalhadores, obtendo, em retribuição, comprometimento e empenho nas tarefas cotidianas. 
Vasconcelos (2001) ressalta, todavia, que o desafio imaginado pelos idealizadores da QVT, de torná-la uma ferramenta gerencial efetiva e não apenas mais um modismo passageiro, persiste.

Existem dois desafios fundamentais, dentre todos, que se apresentam para o universo corporativo atual: a necessidade de uma força de trabalho saudável, motivada e preparada para a atual competitividade e a capacidade da organização atender à demanda de seus funcionários no que se refere a uma melhor QV (SILVA; DE MARCHI, 1997, apud VASCONCELOS, 2001). A questão que se coloca, segundo Monteiro et al. (2011), está relacionada a descobrir quais os fatores que influenciam a decisão das empresas em investir em projetos de QVT.

As iniciativas sob esta denominação ainda são recentes e muitos gestores não se encontram suficientemente convencidos de sua efetividade. Alguns benefícios são presumíveis, entretanto, a correlação entre investimento e retorno não é de todo defensável. O desafio está em estabelecer a relação entre os programas de Gestão de Pessoas e os ganhos que trazem à empresa, levando muitos administradores a deixarem em segundo plano a tarefa de avaliar os resultados do investimento (OLIVEIRA; LIMONGI-FRANÇA, 2005).

Vasconcelos (2001) aponta que o maior obstáculo para a implantação de programas de QVT está na falta de importância estratégica e em sua baixa relevância financeira. Em contraponto, Monteiro et al. (2011) defendem que, em teoria, qualquer investimento em QVT deve acarretar melhoras no desempenho do empregado, refletindo na produtividade e no faturamento da empresa.

Tem-se demonstrado que a satisfação com o trabalho reverte-se em rentabilidade para a organização, seja através de aumentos na produção ou da melhoria no comprometimento. Referemse aqui os resultados de dois estudos que relacionam os programas de QVT com o aumento de produtividade e de receita das empresas e um terceiro que verificou a relação entre a alimentação de trabalhadores e sua QV.

O primeiro estudo, conduzido por Oliveira e Limongi-França (2005), tinha como um dos objetivos investigar a percepção dos administradores sobre a avaliação dos resultados das ações e programas de gestão de pessoas, com ênfase nas questões de QVT. Para tanto, fez uso de um recorte de uma pesquisa exploratória quantitativa realizada alguns anos antes por uma das autoras. Dentre os resultados encontrados, destaca-se que $96,3 \%$ dos administradores afirmaram acreditar que toda empresa deveria ter um programa de QVT, quando questionados acerca da importância de tais programas, e 68\% afirmaram que os empregadores consideram necessárias as ações e os programas de QVT. Enfatiza-se, todavia, o achado empírico de que, 93,2\% dos administradores pesquisados afirmaram que as ações e os programas de QVT interferem positivamente na produtividade das empresas. A partir disso e com base nos objetivos da pesquisa, as autoras concluem que os problemas referentes à avaliação dos programas de QVT das organizações não estão relacionados com a falta de resultados mensuráveis, mas com o desconhecimento de uma metodologia para se avaliar tais resultados.

O segundo estudo que se quer destacar, realizado por Monteiro et al. (2011), teve o objetivo de avaliar o impacto da QVT no faturamento das empresas metalúrgicas de pequeno, médio e grande porte do Estado do Pará. Os achados da pesquisa indicaram que existe um impacto positivo do nível de satisfação dos funcionários e dos gestores e do nível de investimento em QVT no faturamento das empresas. Os autores concluíram que as variáveis investimento em QVT e percepção de satisfação com ações e programas de QV oferecidos estão associados positivamente com o faturamento das empresas estudadas. Conforme ressaltam Monteiro et al. (2011), os resultados encontrados com a pesquisa evidenciam o papel do fator humano e a necessidade de sua gestão para que se garantam vantagens competitivas sustentáveis e se contribua para o desenvolvimento das pessoas e das empresas. Ao relacionarem a QVT a mudanças positivas no faturamento e na produtividade, os estudos apresentados desvelam o papel estratégico dessa ferramenta, cujas ações e programas podem beneficiar diretamente os trabalhadores, repercutindo em ganhos para as organizações.

O terceiro e último estudo, de caráter quali-quantitativo, conduzido por Sebastião et al. (2015), objetivou avaliar as relações existentes entre os hábitos alimentares e a QV de trabalhadores de uma empresa de fornecimento de energia do interior do Paraná. Constatou-se índice satisfatório 
para a QV global em sua maioria, ainda que a pesquisa tenha identificado algumas inadequações na dieta dos trabalhadores. O estudo em questão não encontrou, portanto, relação entre a percepção de QV dos pesquisados e seus hábitos alimentares. Tal achado aponta para o caráter singular e subjetivo da experiência de QV, uma vez que mesmo não dispondo de alimentação adequada, os pesquisados referiram boa $\mathrm{QV}$, provavelmente influenciada por outros fatores.

Estas e outras evidências indicam a necessidade dos responsáveis pela Gestão de Pessoas estarem atentos aos benefícios, tanto para os colaboradores - individual e coletivamente - quanto para a empresa como um todo, advindos da QVT, a partir da correta implantação e avaliação de iniciativas e programas neste campo.

\section{Considerações finais}

Por se tratar de um conceito subjetivo e multidimensional, muitos elementos estão envolvidos na QVT. Qualquer tentativa de enumerá-los e agrupá-los, por melhor e mais completa que seja, será vã e relativa a quem a fizer, pois sempre algo lhe escapará. Em vista disso, verifica-se que a experiência do que seja QV (no trabalho e fora dele) tem algo de particular.

Pessoas que, muitas vezes, dispõem do mínimo para sobreviver referem um nível de bemestar que não é encontrado em populações afortunadas. O que à primeira vista parece contraditório, a partir de uma análise mais depurada, revela-se compreensível ao se aceitar que a experiência de bem-estar, ou, se preferir, de QV, é substancialmente particular.

Cada sujeito elencará o que lhe importa para que se sinta bem, ainda que, inegavelmente, boa parte dos fatores que comporão a lista serão oriundos dos valores sociais do tempo próprio, isto é, sintonizados com aquilo que a cultura e a comunidade em que este se insere apresentam-lhe como digno de valor.

Portanto, a complexidade da avaliação da QVT bem como da elaboração de intervenções nesta área está diretamente relacionada ao fator eminentemente individual que caracteriza tal construto. Por essa razão, ao se pensar a QVT, tanto em intervenções pontuais quanto em sua gestão de forma ampla e integrada a outros programas, algumas das perguntas a se fazer são: "quais são as necessidades destes trabalhadores?", "de que precisam para se sentirem valorizados e reconhecidos?" e "o que pode contribuir para que se sintam melhor no e com seu trabalho neste momento e ao longo do tempo?".

As respostas a estas perguntas fornecerão importantes pistas do caminho a se seguir. Projetos elaborados a partir de modelos preconcebidos tendem a ter pouco ou nenhum efeito, de maneira que a escuta atenta aos sujeitos que serão contemplados pelas ações de QVT é imprescindível para a ampliação das possibilidades de êxito, assim como ocorre com outras iniciativas que envolvem o fator humano na Gestão de Pessoas das organizações.

O conceito de QVT cunhado por Limongi-França (1997), atualmente um dos mais aceitos, explicita que a tônica está no conjunto de ações a ser implantado com vistas à melhoria do ambiente de trabalho. Resta, ainda, um importante campo a ser explorado no que tange à verificação da efetividade das iniciativas. Desvela-se, desse modo, a necessidade de estudos empíricos voltados para a aferição e a compreensão dos resultados concretos dos projetos de QVT, como os apresentados acima, sejam realizados.

\section{Referências}

ANGRAD. Associação Nacional dos Cursos de Graduação em Administração. Qualidade de Vida no Trabalho e Qualidade de Vida: uma proposta integradora. 2012. Disponível em: <http://www.angrad.org.br/_resources/files/_modules/producao/producao_502_201212051834228e 9c.pdf>. Acesso em: 10 mar. 2015. 
BOWDITCH, J. L.; BUONO, A. F. Elementos de comportamento organizacional. São Paulo: Pioneira, 1992.

DESSEN, M. C.; PAZ, M. G. P. Bem-estar pessoal nas organizações: o impacto de configurações de poder e características de personalidade. Psicologia: Teoria e Pesquisa, v. 26, n. 3, p. 549-556, 2010. crossef

FERNANDES, E. Qualidade de vida no trabalho: como medir para melhorar. 5. ed. Salvador: Casa da Qualidade, 1996.

FERREIRA, M. C.; ALVES, L.; TOSTES, N. Gestão de qualidade de vida no trabalho (QVT) no serviço público federal: o descompasso entre problemas e práticas gerenciais. Psicologia: Teoria e Pesquisa, v. 25, n. 3, p. 319-327, 2009. Crossef

GARCIA, E. O. P. O conteúdo significativo da qualidade de vida no trabalho para funcionários públicos de uma secretaria de saúde. Revista Eletrônica Gestão e Serviços, v. 1, n. 1, p. 76-94, 2010. Crossef

HACKMAN, J. R.; OLDHAM, G. R. Development of the Job Diagnostic Survey. Journal of Applied Psychology, v. 60, n. 2, p. 159-170, 1975. Crossef

HUSE, E.; CUMMINGS, T. Organization development and change. 3. ed. St. Paul: West Publishing Co, 1985.

LIMONGI-FRANÇA, A. C. Qualidade de vida no trabalho - QVT: conceitos e práticas nas empresas da sociedade pós-industrial. 2. ed. 3. reimpr. São Paulo: Atlas, 2008.

LIMONGI-FRANÇA, A. C. Qualidade de vida no trabalho: conceitos, abordagens, inovações e desafios nas empresas brasileiras. Revista Brasileira de Medicina Psicossomática, v. 1, n. 2, p. 79-83, 1997.

MONTEIRO, E. M. A.; DINIZ, F. J. L. S.; LIMONGI-FRANÇA, A. C.; CARVALHO, J. V. F. O impacto da qualidade de vida no trabalho (QVT) no faturamento das indústrias metalúrgicas do Estado do Pará. Revista de Administração da UEPG, v. 2, n. 1, p. 18-33, 2011.

NADLER, D. A.; LAWLER, E. E. Quality of work life: perspectives and directions.

Organizational Dynamics, Amsterdam, v. 11, n. 3, p. 20-30, 1983. Crossef

OLIVEIRA, P. M.; LIMONGI-FRANÇA, A. C. Avaliação da gestão de programas de qualidade de vida no trabalho. RAE - eletrônica, v. 4, n. 1, 2005. crossef

RODRIGUES, M. V. C. Qualidade de vida no trabalho: evolução e análise no nível gerencial. 6. ed. Petropolis: Vozes, 1999.

SARAJI, G. N.; DARGAHI, H. Study of quality of work life. Iranian Journal of Public Health, v. 35 , n. 4, p. 8-14, 2006.

SEBASTIÃO, H. M.; TIMOSSI, M. S.; BORTOLOZO, E. A. F. Q.; PILATTI, L. A. Avaliação da qualidade de vida e do consumo alimentar de funcionários de uma empresa de fornecimento de energia elétrica. Revista Brasileira de Qualidade de Vida, v. 70, n. 1, p. 12-19, 2015. 
STEFANO, S. R.; GATTAI, M. C. P.; ROSSINI, V.; LIMONGI-FRANÇA, A. C. Satisfação da qualidade de vida no trabalho com relação aos fatores biopsicossociais e organizacionais: um estudo comparativo entre docentes das universidades pública e privada. Revista Gerenciais, v. 5, p. 35-44, 2006.

THE WHOQOL GROUP. The World Health Organization quality of life assessment (WHOQOL): positional paper from the World Health Organization. Social Science \& Medicine, v. 41, p. 14031409, 1995. crossef

VASCONCELOS, A. F. Qualidade de vida no trabalho: origem, evolução e perspectivas. Caderno de Pesquisas em Administração, v. 8, n. 1, p. 23-35, 2001.

VELOSO, E. F. R.; SCHIRRMEISTER, R.; LIMONGI-FRANÇA, A. C. A influência da qualidade de vida no trabalho em situações de transição profissional: um estudo de caso sobre desligamento voluntário. Revista Administração e Diálogo, v. 9, n. 1, p. 35-58, 2007.

WALTON, R. E. Quality of working life: what is it?. Sloan Management Review, v. 15, n. 1, p. 11-21, 1973.

WERTHER, W. B.; DAVIS, K. Administração de pessoal e recursos humanos. São Paulo: McGraw Hill do Brasil, 1983.

WESTLEY, W. A. Problems and solutions in the quality of working life. Human Relations, v. 32, n. 2, p. 111-123, 1979. Crossef 